\title{
Criptogenetic Cerebral Ischemia and Spongious Atrial Septum. A New Culprit?
}

\section{Baglini Roberto*}

Department of Interventional Cardiology, Palermo, Italy

\author{
Abstract \\ A case of unusual atrial septal anatomy with right-to-left shunting in a patient with cryptogenetic cerebral ischemia \\ is presented. Percutaneous correction and technical tips are described.
}

\section{Introduction}

The appropriate treatment strategy for secondary stroke prevention in patients with cryptogenic stroke and Patent Foramen Ovale (PFO) remains challenging. The clinical and anatomic variables reported to be risk factors associated with stroke recurrence include older age [1], large PFO [2-5] and large right-to-left shunting [6] and combined atrial septal aneurysm $[7,8]$.

Patent Forame Ovale (PFO) is an anatomical variant of the atrial septum, providing communication between the atrial chambers of the heart through fossa ovalis on the right side and the ostium secundum on the left side. Septum primum acts as a one-way valve allowing blood flow from the right to left atria, bypassing the lungs. This septum normally remains patent before birth and closes with the first breath of air that a baby takes because of increased left sided pressures [9].

Autopsy studies have shown an overall prevalence of $27 \%$ in the general population, decreasing with increasing age (35\% and $20 \%$ in age groups less than 30 years and more than 80 years, respectively) $[10,11]$. This could be secondary to either selective mortality of patients with PFO with age or late spontaneous closure.

Transthoracic Echocardiography (TTE) diagnosis requires detection of a shunt with either color Doppler or agitated saline contrast with Valsalva maneuver, and its prevalence in the population varies anywhere between $10 \%$ to $22 \%$ with this technique [12-15].

Trans-Cranial Doppler (TCD) provides the possibility to show the specific cerebral flow disturbance in case of right to left shunt during Valsalva maneuver. It confirms PFO (patho) physiology significance $[16,17]$.

This report deals with a patient with trans-cranial Doppler positivity and non-apparent PFO with initial impossibility to cross the atrial septum during PFO percutaneous closure attempts.

\section{Case Report}

A 49 year old Caucasian male came to our Outpatient Clinic after several transient ischemic neurological attacks without any evidence of Carotid, aortic or cardiac embolic disease. Hypercoagulability screening tests were completely negative.

TTE had confirmed the presence of right to left shunt at atrial septum level, according to a positivity of TCD with curtain effect during Valsalva maneveur. Patient was thus scheduled for PFO percutaneous closure.

The procedure was performed during general anesthesia, orotracheal intubation, and Trans-Esophageal Echo (TEE) monitoring. Atrial septum showed some grade of mixoid degeneration with increased thickness $(4 \mathrm{~mm}$ ) (Figure 1). Surprisingly, no evidence of septal defects and/or PFO was shown, as neither a 5 F MP catheter nor the common angiographic wires ( 0.021 to 0.035 ") were able to cross the septum in spite of several and accurate attempts.

However, echo-contrastography (agitated saline solution from the venous femoral route) during Valsalva maneveur showed right to left passage of multiple swirling contrast jet through the septal wall (Figures 2 and 4). This unusual pattern of right to left shunting suggested the possibility to engage a small wire into and through the septum.

In fact, after multiple attempts, the septum was crossed by a 300 $\mathrm{cm}$ long 0,014 " coronary medium weight guidewire followed from a 5F MP catheter.

Following the left atrium selective catheterization, a high support angiographic 0.035 " wire was left into the left superior pulmonary vein and a $9 \mathrm{~F}$ Mullins long sheath was easily inserted into the left atrium (Figure 3).

Then a 23/25 mm Figulla atrial septal occluder $\left(\right.$ Occlutech $\left.^{\circledR}\right)$ was used aiming to stent the major part of the septum without encroaching

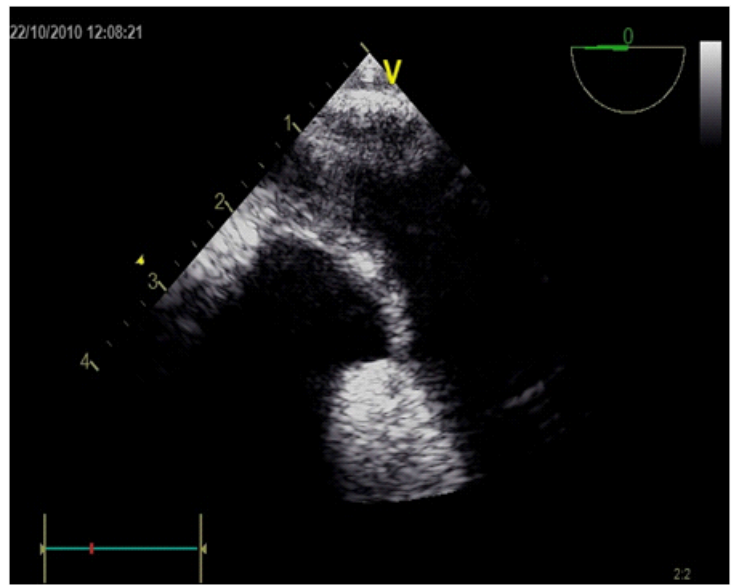

Figure 1: Atrial septal mixoid degeneration

*Corresponding author: Dr. Roberto Baglini, MD, PhD, IsMeTT, UPMC, Department of Interventional Cardiology, Via Tricomi 1, 90100 Palermo, Italy, Tel: 0039-091-2192477; E-mail: rbaglini@ismett.edu

Received November 06, 2012; Accepted December 05, 2012; Published December 07, 2012

Citation: Roberto B (2012) Criptogenetic Cerebral Ischemia and Spongious Atria Septum. A New Culprit? J Clin Case Rep 2:233. doi:10.4172/2165-7920.1000233

Copyright: (c) 2012 Roberto B. This is an open-access article distributed under the terms of the Creative Commons Attribution License, which permits unrestricted use, distribution, and reproduction in any medium, provided the original author and source are credited. 


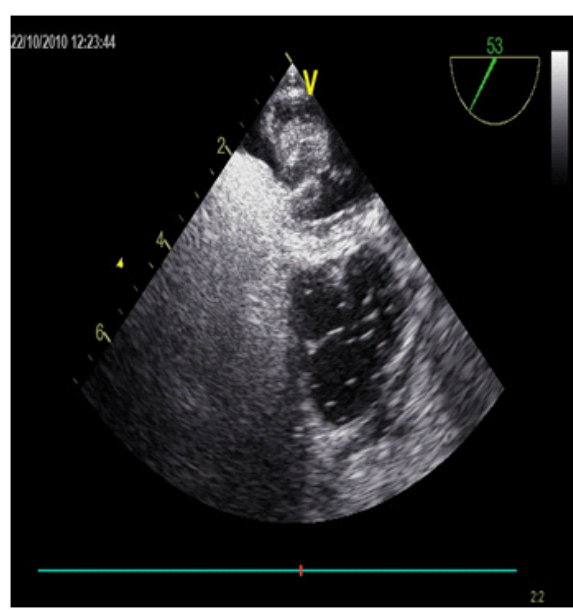

Figure 2: TEE: no PFO evidence and right to left shunting during Valsava.

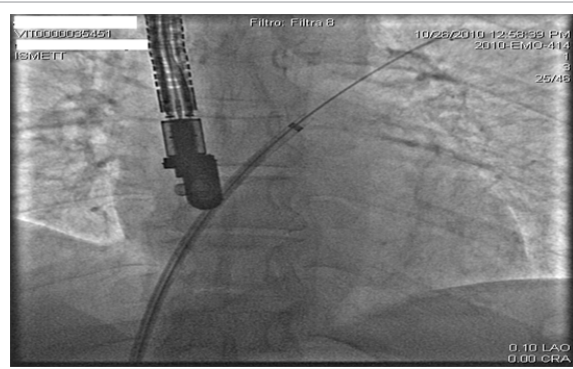

Figure 3: Hardware through the atrial septum.

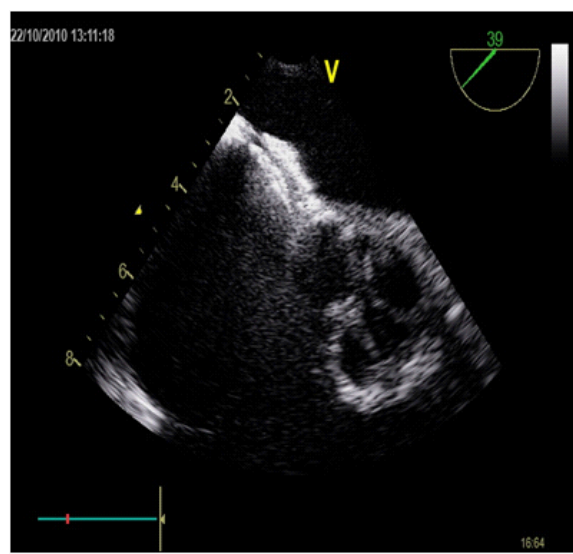

Figure 4: On site occluding atrial septal prosthesis.

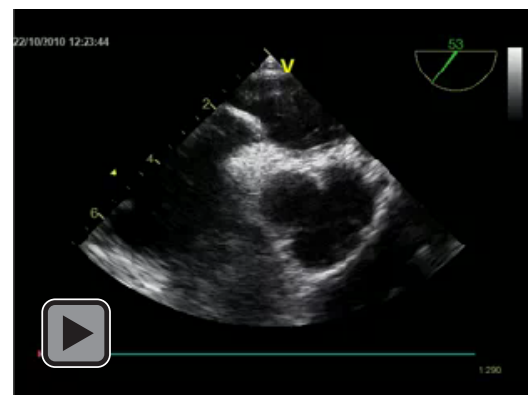

Movie 1 the surrounding anatomic structures (Aorta, mitral valve, caval veins) (Figure 4).

After the septal occluder deployment, the right to left shunt during Valsalva maneveur rapidly disappeared with persistence of only minimal intra-prosthetic shunt.

\section{Discussion}

PFO initial screening is generally done with TTE using color Doppler and agitated saline contrast [13]. TCD with Valsalva and bubble test can also be used as an initial screning test (with higher sensitivity and lower specificity than TTE).

Administration of contrast through the femoral vein as opposed to the ante-cubital vein has shown to increase sensitivity of detection of PFO. This is due to the fact that blood from the superior vena cava is directed towards the tricuspid valve, while venous return from the inferior vena cava is directed towards the PFO $[18,19]$.

During interventional approach, PFO is generally easily crossed by a common MP catheter or a 0.035 " angiographic wire.

Sometimes, in cases of complex septal anatomy (multi-cribrosity, hypertrophic Eustachian valve, septal aneurysm) crossing the atrial septum may request multiple attempts under the guide of TEE.

In this reported case, no definite communication between right and left atrium through a patent foramen ovale and/or a (micro) septal defect was present. However, the atrial septum, that showed some thickening and looked non-homogeneous in the region of the fossa ovalis, let echocontrast pass from right to left through multiple sites during Valsalva maneveur, apparently behaving as a spongious reservoir.

There are no definite cases described in literature of such septal behavior, while some report of non-PFO embolic anatomy such as the so called pouch septum does exist $[20,21]$.

In the described case, the atrial septum behave like a reservoir, ejecting blood from right to left as squeezed by the increased thoracic pressure (Valsalva). A mechanical approach with stenting of a wide part of the atrial septum was adopted in the hope to reduce the propensity to paradoxical shunting of blood in this patient.

A transeptal puncture was avoided as a thin coronary wire was able to pass from right to left, probably through intraseptal micro channels.

This anatomic variant was thus defined spongious micro-channeled atrial septum.

The patient is maintained under strict clinical (double oral antiplatelet therapy) and TTE and TCD follow up to confirm the favorable evolution of the septum stenting procedure.

\section{References}

1. Homma S, Di Tullio MR, Sacco RL, Sciacca RR, Mohr JP et al. (2004) Age as a determinant of adverse events in medically treated cryptogenic stroke patients with patent foramen ovale. Stroke 35: 2145-2149.

2. Homma S, Di Tullio MR, Sacco RL, Mihalatos D, Li Mandri G, et al. (1994) Characteristics of patent foramen ovale associated with cryptogenic stroke. a biplane transesophageal echocardiographic study. Stroke 25: 582-586.

3. Hausmann D, Mugge A, Daniel WG (1995) Identification of patent foramen ovale permitting paradoxic embolism. J Am Coll Cardiol 26: 1030-1038.

4. Stone DA, Godard J, Corretti MC, Kittner SJ, Sample C, et al. (1996) Patent foramen ovale: association between the degree of shunt by contras transesophageal echocardiography and the risk of future ischemic neurologic events. Am Heart J 131:158-161. 
5. Schuchlenz HW, Weihs W, Horner S, Quehenberger F (2000) The association between the diameter of a patent foramen ovale and the risk of embolic cerebrovascular events. Am J Med 109: 456-462.

6. De Castro S, Cartoni D, Fiorelli M, Rasura M, Anzini A, et al. (2000) Morphological and functional characteristics of patent foramen ovale and their embolic implications. Stroke 31: 2407-2413.

7. Meissner I, Khandheria BK, Heit JA, Petty GW, Sheps SG, et al. (2006) Patent foramen ovale: innocent or guilty? Evidence from a prospective populationbased study. J Am Coll Cardiol 47: 440-445.

8. Mas JL, Arquizan C, Lamy C, Zuber M, Cabanes L, et al. (2001) Recurren cerebrovascular events associated with patent foramen ovale, atrial septal aneurysm, or both. N Engl J Med 345: 1740-1746.

9. Gill EA Jr (2005) Definitions and pathophysiology of the patent foramen ovale: broad overview. Cardiol Clin 23: 1-6.

10. Lechat P, Mas JL, Lascault G, Loron P, Theard M, et al. (1988) Prevalence of patent foramen ovale in patients with stroke. N Engl J Med 318: 1148-1152.

11. Hagen PT, Scholz DG, Edwards WD (1984) Incidence and size of patent foramen ovale during the first 10 decades of life: an autopsy study of 965 normal hearts. Mayo Clin Proc 59: 17-20.

12. Gill EA Jr, Quaife RA (2005) The echocardiographer and the diagnosis of patent foramen ovale. Cardiol Clin 23: 47-52.

13. Gramiak R, Shah PM, Kramer DH (1969) Ultrasound cardiography: contrast studies in anatomy and function. Radiology 92: 939-948.
14. Woods TD, Patel A (2006) A critical review of patent foramen ovale detection using saline contrast echocardiography: when bubbles lie. J Am Soc Echocardiogr 19: 215-222.

15. Ha JW, Shin MS, Kang S, Pyun WB, Jang KJ, et al. (2001) Enhanced detection of right-to-left shunt through patent foramen ovale by transthoracic contrast echocardiography using harmonic imaging. Am J Cardiol 87: 669-671.

16. Roste DW, Reisener M, Kemény V, Dittrich R, Schulte-Altedorneburg G, et al. (1999) Contrast transcranial Doppler ultrasound in the detection of rightto-left shunts. Reproducibility, comparison of 2 agents, and distribution of microemboli. Stroke 30: 1014-1018.

17. Nedeltchev K, Mattle HP (2006) Contrast-enhanced transcranial Doppler ultrasound for diagnosis of patent foramen ovale. Front Neurol Neurosci 21 206-215.

18. Roberson DA, Javois AJ, Cui W, Madronero LF, Cuneo BF, et al. (2006) Double atrial septum with persistent interatrial space: echocardiographic features of a rare atrial septal malformation. J Am Soc Echocardiogr 19: 1175-1181.

19. Breithardt OA, Papavassiliu T, Borggrefe M (2006) A coronary embolus originating from the interatrial septum. Eur Heart J 27: 2745.

20. Javois AJ, Roberson DA (2007) Unusual atrial septal anatomy resulting in an interatrial chamber: the true triatrial heart? Pediatr Cardiol 28: 224-228.

21. Krishnan SC, Salazar M (2010) Septal pouch in the left atrium: A new anatomical entity with potential for embolic complications. JACC Cardiovasc Interv 3: 98-104. 